\title{
Gümüşi Ihlamur (Tilia tomentosa Moench) doğal popülasyonlarında çiçek yağ verimini etkileyen fizyografik faktörler
}

\section{Physiographic factors affecting oil yield in natural populations of silver linden (Tilia tomentosa Moench)}

\author{
Salih PARLAK ${ }^{1}$ iD, Oktay GÖNÜLTAŞ ${ }^{\text {iD }}$, Harun HAMURCU ${ }^{3}$ iD \\ ${ }^{1}$ Bursa Teknik Üniversitesi Orman Fakültesi Orman Mühendisliği Bölümü Bursa, Türkiye \\ 2Bursa Teknik Üniversitesi Orman Fakültesi Orman Endüstri Mühendisliği Bölümü Bursa, Türkiye \\ ${ }^{3}$ Bursa Teknik Üniversitesi Orman Fakültesi Orman Ürünleri Yüksek Lisans Programı Bursa, Türkiye
}

Eser Bilgisi/Article Info
Araştırma makalesi/Research article
DOI: 10.17474 /artvinofd.487013
Sorumlu yazar/Corresponding
author
Salih PARLAK
e-mail: salih.parlak@btu.edu.tr
Geliş tarihi / Received
23.11.2018
Düzeltme tarihi / Received in revised
form
01.03.2019
Elektronik erişim / Online available
04.04.2019
Anahtar kelimeler:
Ihlamur çiçeği
Tilia tomentosa
Yağ verimi
Fizyografik faktörler
Bursa
Yalova
Keywords:
Linden flower
Tilia tomentosa
Oil yield
Physiographic factors
Bursa
Yalova

\begin{abstract}
Özet
Geleneksel halk hekimliğinde Ihlamur türleri (Tilia sp.)'nin tıbbi amaçlı kullanımı yüzyıllardır bilinmektedir. Kış mevsiminin en çok tüketilen bitki çaylarından biridir.Üretimin büyük bir kısmı Bursa ve Yalova illerindeki doğal gümüşi ıhlamur (Tilia tomentosa Moench.) ormanlarından temin edilmektedir. Çiçek üretimi amacıyla kurulmuş plantasyonlar bulunmadığından, doğal ormanlardan yapılan üretim aşırı tahripkar olmaktadır. Bu tahribatın önüne geçilebilmesi için mutlaka çiçek verimi ve kalitesi yüksek bireyler seçilip klonal yolla çoğaltılarak çiçek üretimine yönelik plantasyonların kurulması gerekmektedir. Doğal popülasyonlarda çiçeklenme zamanı, çiçek rengi, iriliği, kokusu vb. unsurların değişkenlik arz ettiği görülmektedir. Bu çalışmada Bursa-Gökçeören, Karacabey-Yeniköy ve Yalova-Esenköy'deki doğal popülasyonlardan tam çiçeklenme zamanında toplanan örneklerin yağ miktarları Clevenger cihazı ile belirlenmiştir. Yağ verimine de etkili olabilecek mevki, rakım, bakı, eğim, taç yönü, çiçek rengi gibi faktörler incelenmiştir. Yağ miktarları ile fizyografik faktörler arasındaki ilişkiler irdelenmiştir. Yapılan çalışma sonucunda; ıhlamur çiçeklerinin yağ veriminin yörelere ve rakıma göre değişiklik gösterdiği, eğim ve bakının ise etkisinin olmadığı belirlenmiştir. Kapalılık, ağaç taç çapı, çiçek toplanan taç yönü, çiçek rengi, tomurcuk ve çiçeklenme durumlarının yağ verimini etkilemediği belirlenmiştir.
\end{abstract}

\begin{abstract}
The medicinal use of linden species (Tilia sp.) in traditional folk medicine has been known for centuries. It is one of the most consumed herbal teas, especially in winters. A large part of the production is obtained from natural silver linden (Tilia tomentosa Moench.) forests in Bursa and Yalova provinces. Since there aren't any plantations for flower production, production from natural forests creates extreme damages. To prevent this destruction, it is necessary to establish flower production plantations where the high-quality flowers are selected and clonal propagation performed. It is seen that in natural populations, flowering time, flower color, bigness, odor, etc. vary. In this study, The oil amounts of samples collected at the full blooming time from Bursa-Gökçeören, Karacabey-Yeniköy and Yalova-Esenköy Natural Populations were determined using Clevenger apparatus. The factors such as location, altitude, aspects, slope, crown aspect, flower color, affecting the oil yield were investigated. Finally, Correlations between oil amounts and physiographic factors were examined.As a result of the study; It was determined that the oil yield of the linden flowers varies according to the location and the altitude, while the slope and aspects showed no effect. It was also found that crown closure, tree crown diameter, crown aspect, flower color, bud, and full blooming did not affect the oil yield.
\end{abstract}

\section{GiRiş}

Türkiye; Akdeniz, Avrupa-Sibirya ve İran-Turan olmak üzere üç farklı bitki coğrafya bölgesini kapsamaktadır. Bu bölgelerin her biri kendi endemik türlerine ve doğal ekosistemlerine sahip (Tan 2010) olup 11466 doğal, 3649 endemik türü bulunmaktadır (Güner vd. 2012).Türkiye'de dört türle temsil edilen ıhlamur (Tilia rubra subsp. Caucasica (Rupr.) V. Engl., Tilia cordata Mill., Tilia platyphyllos Scop., Tilia tomentosa Moench) orman alanlarımızın \% 0.06'sını kaplamakta ve bunun yaklaşık yarısını gümüşi ıhlamur (Tilia tomentosa) oluşturmaktadır (Davis 1967; Korkut 2011).Gümüşi Ihlamurun yüksekliğe bağlı olarak üç ekotipi bulunmaktadır (Kalmukov 1994). Yaprakların alt yüzü gümüşi beyaz, yıldız tüylü çiçekleri beş parçalı, sarımsı renkli, kendine has özel ve kuvvetli kokusu vardır (Uslu 2004). Geleneksel olarak kışın çay şeklinde tüketilen, orman halk ilişkilerine önemli katkılar 
sağlayan ıhlamur çiçeği üretiminin yarıdan fazlası Bursa ve Yalova illerindeki doğal ormanlardan karşılanmaktadır (Tuttu vd. 2017). Orman Genel Müdürlüğü istatistiklerine göre 28 yıllık ortalama üretim 37 ton olup son yıllarda üretim artmış ve 2017' de 208 ton olarak gerçekleşmiştir (URL 1).

Gümüşi ıhlamurun çiçek ve tomurcukları yüzyıllardır teskin edici (Allio et al. 2015), hafif gerginliklerde sakinleştirici ve terletici olarak kullanılmaktadır (AguirreHernandez et al. 2006; Cardenas-Rodriguezetal 2014; Herrera-Ruiz et al. 2008; Loscalzo et al. 2009). Tedavi edici etkileriyle ilgili ilk bulgular birkaç yüzyıl öncesine kadar uzanmaktadır (Alston 1770). Gümüşi ıhlamurun merkezi sinir sistemi üzerindeki sakinleştirici etkisi iyi bilinmektedir (Viola et al. 1994). Ayrıca yaprak ve çiçekleri terletici, balgam söktürücü, grip, öksürük, migren, çeşitli sindirim problemleri, spazm türleri, karaciğer ve safra kesesi rahatsızıklarının tedavisinde kullanılmaktadır (Peev et al. 2009). Gümüşi ıhlamur çiçekleri bronşit, nezle ve öksürük gibi sağıık sorunlarına karşı dünyanın her yerinde bilinmekte ve kullanılmaktadır (Gruenwald et al. 2000; Anonymous 2012; Chinou 2012). Hazmettirici, balgam söktürücü ve terletici etkilerinden dolayı özellikle soğuk algınlıklarında halk arasında yaygın olarak tüketilmektedir. Müsilaj etkisi ile boğaz şişkinliklerini azaltıcı etkisi bulunmaktadır (Bradley 1992; Toker vd. 1997; Toker vd. 1999; Akbulut ve Bayramoğlu, 2013). Gümüşi ihlamur Türk halk hekimliğinde de benzer rahatsızlıklarda kullanılmaktadır. Çoğu zaman pazarlarda sade çiçek olarak veya brahteli çiçek şeklinde satılmaktadır (Toker vd. 2004). Ihlamur çayında çok güçlü antioksidan içeren flavonoid yapısında polifenoller olduğu ve bu bileşiklerin kateşin ve türevlerinden kaynaklandığı, antioksidan içeren bileşiğin hücreleri serbest radikal hasarlarına karşı $C$ ve $E$ vitaminlerinden çok daha iyi koruduğu ve immun sistemi desteklediği gösterilmiştir (Vinson et al. 1995; Georgiev et al. 2017). Çok güçlü bir antioksidan aktiviteyi sağlayan ve ıhlamur çayında bulunan flavonollerin (glycosides, quercetin, kaempferol, hydroxycinnamic acidsve ellagitannins gibi) C vitamininden $20 \mathrm{kez}$ daha etkili olduğu belirlenmiştir (Craig 1999; leri et al. 2015). Ihlamur arıcılık için de önemli bir ağaçtır. Ihlamur çiçeğinin önemli bir özelliği ıhlamur balının temel bileşenlerinden birisi olması ve arıcılıkta yaygın olarak yararlanılmasıdır. Hoş kokulu olmasından dolayı çiçekleri bal arıları ve diğer böcekler için oldukça cezbedicidir (Baytop 1996; Baytop 1999; Özyurt 1992; Sıralı ve Deveci 2002; Özen 2004). Normal bala göre daha koyu ve kıvamlı olan ıhlamur balı birçok hastalığın tedavisinde kullanılmaktadır (Uslu 2004). Bir koloni arının bir ıhlamur ağacından $16 \mathrm{~kg}$ bal yapabildiği saptanmıştır (Sorkun 1995). Odunu da birçok alanda kullanılmaktadır (Tsoumis 2002).

Gümüşi Ihlamurda genellikle çiçek yağ bileşenlerini belirleme çalışmaları yapılmış (Gegiu 2008; Anonymous 2012; Kıvrak vd. 2017; Şahin vd. 2018) fakat yağ verimine dönük çok az çalışmaya rastlanılmıştır. Popülasyon çeşitliliği ortalaması 0.50 olup (Birbilener 2015) çiçek yapıları bakımından doğal ormanlarda çok farklı bireylere rastlanmaktadır. Bu husus göz önüne alınarak popülasyonların taranması ve çiçek yağ verimi farklı bireylerin ortaya konması amaçlanmıştır. Ayrıca çiçeklerde yağ verimini etkileyen fizyografik faktörlerin etkisi ortaya konmaya çalışılmıştır. Üç farklı popülasyondan çiçekler toplanarak yağ verimleri belirlenmiştir.

\section{MATERYAL ve YÖNTEM}

\section{Bitki Materyali}

Çalışmanın materyalini Bursa-Gökçeören, KaracabeyYeniköy ve Yalova Esenköy'de doğal yayılış gösteren saf veya karışık gümüşi ıhlamur ormanları oluşturmaktadır (Şekil 1). 2017 yılı 12-18 Haziran tarihlerinde üç farklı popülasyonda toplam 110 ağaçtan çiçek örneklemeleri yapılmıştır. Çiçekler tacın dış kısımlarından, yerden 3-5 metre yükseklikten, 3-4 yaşlı dallar kesilerek her ağaçtan en az 500 gr ıhlamur çiçekleri toplanmıştır. Brahteleri ile koparılan çiçekler hemen polietilen torbalara konularak ağızları bağlanmış ve su kaybetmeleri önlenmiştir. Laboratuvara getirilen örnekler tartıldıktan sonra raflara konularak ışık görmeden hava kurusu hale gelinceye kadar iki hafta süreyle kurutulmuştur. Analiz zamanına kadar kağıt torbalarda oda sıcaklığında bekletilmiştir. Analizlerde sekiz adet Clevenger aparatı ve dörtlü sabit mantolu ısıtıcılar kullanılmıştır. 
Şekil 1. Çalışma alanlarının konumları

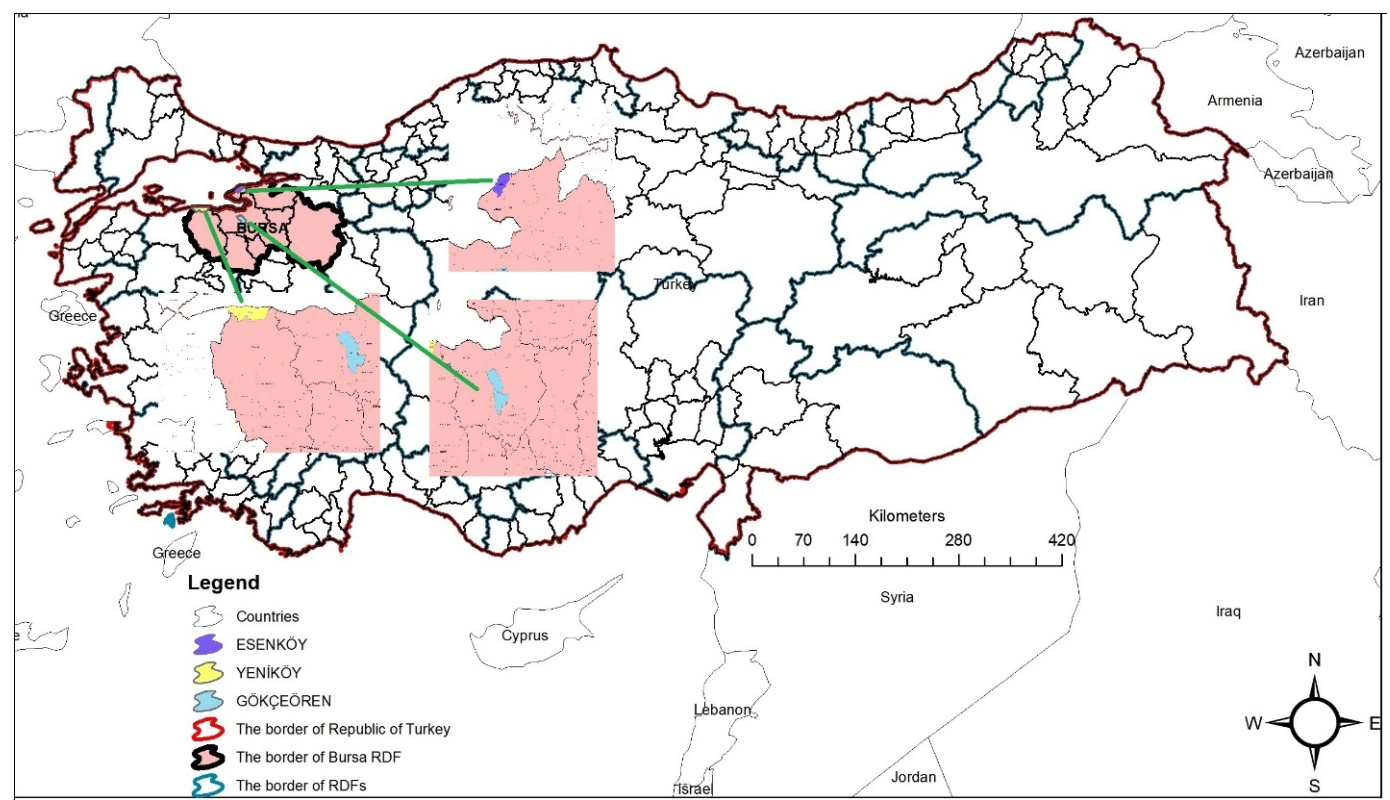

\section{Yöntem}

\section{Ihlamur çiçeklerinin toplanması}

Araştırma alanının fizyografik özelliklerini belirlemek için arazi şekli, mevki, bakı, yükselti, yamaç eğimi, yerin koordinatları GPS ile alınarak envanter karnesine kaydedilmiştir. Üç popülasyondan alınacak örnek sayıları ıhlamur popülasyonunun alansal büyüklüğüne orantılı olarak belirlenmiştir. Yükselti basamakları 0-200, 200-400 ve 400-600 metre olarak ayrılmıştır. Eğimin belirlenmesinde örnek alanın bulunduğu mevki dikkate alınmıştır. İklim özelliklerinin belirlenmesi için en yakında bulunan Bursa ve Yalova meteoroloji istasyonu verileri kullanılmıştır. Araştırma alanının iklim tipleri, ortalama yağış ve ortalama sıcaklık değerleri kullanılarak Thorntwaite (1948) yöntemine göre belirlenmiştir. Meteoroloji istasyonu verileri araştırma alanına uyarlanarak sıcaklık değerleri her $100 \mathrm{~m}$ 'de 0.5 o $C$ azaltılmış, yağış değerleri ise her 100 m'de 54 mm arttırılmıştır (Çepel, 1988; Özyuvacı, 1999). Çiçek toplanan taç yönü, kapalılık, çiçeklenme durumu, çiçek rengi gibi yağ miktarını etkileyebilecek faktörler envanter karnelerine işlenmiştir.

\section{Örneklerin hazırlanması ve yağ analizlerinin yapılması}

Ihlamur çiçekleri iki hafta süresince kağıtlar üzerine serilerek kurutulmuş, daha sonra yağ analizi yapılana kadar kese kağıtlarında muhafaza edilmiştir. Ihlamur çiçeklerinin brahteleri farklı boyutlarda olduğundan standart ölçüm yapabilmek için brahteleri koparılarak analizlerde sadece çiçek kurulları kullanılmıştır. Kurutulmuş çiçeklerden $100 \mathrm{~g}$ tartılmış ve bir litrelik şilifli balonlara konularak $500 \mathrm{ml}$ saf su ilave edilmiştir. Clevenger tipi su buharı destilasyon düzeneğinde 3 saat boyunca kaynatılarak çiçek yağları elde edilmiştir. İstatistiki anlamda farklılıkları belirlemek için $p<0.05$ önem düzeyinde ANOVA ve Duncan testleri yapılmıştır.

\section{BULGULAR ve TARTIŞMA}

\section{Klimatolojik Bulgular}

Bursa'ya ait 1926-2016 yılları arasındaki meteorolojik verilere göre yıllık ortalama sıcaklık $14.6^{\circ} \mathrm{C}$ ve yıllık yağış ortalaması $707.5 \mathrm{~mm}$ dir. Aynı yıllarda Yalova'ya ait yıllık ortalama sıcaklık $14.7^{\circ} \mathrm{C}$ ve yıllık yağış ortalaması 749.8 mm bulunmuştur. Thorntwaite (1948) yöntemiyle yapılan tespitlere göre Bursa; nemli, orta sıcaklıkta (mezotermal), su noksanı yaz mevsiminde ve çok kuvvetli olan, okyanus iklimine yakın iklim tipine sahiptir. Yalova ise yarı nemli, orta sıcaklıkta (mezotermal), su noksanı yaz mevsiminde ve çok kuvvetli olan, okyanus iklimine yakın iklim tipine sahiptir.

\section{Odunsu Floristik Yapı}

Çalışma alanlarında ıhlamur ile karışıma giren odunsu türler; Castanea sativa Mill. (Kestane), Quercus cerris L. (Saçlı Meşe), Quercus petraea (Mattuschka) Lieb. (Sapsız Meşe), Corylus avellana L. (Adi fındık), Laurus nobilis L. (Defne), Daphne pontica L. (Sırımbağı) Hedera helix L. , 
Alnus glutinosa (L.) Gaertn., Styrax officinalis L., Rubus ssp., Erica ssp., Arbutus andrachne L., Cistus salviifolius L., C. Laurifolius L., Sorbus torminalis (L.) Crantz, Rhus coriaria L., Alnus glutinosa (L.) Gaertn, Platanus orientalis L., Populus tremula L., Carpinus betulus L., Fraxinus ornus L., F. angustifolia Vahl., Rosa canina L., Cornus mas L., Corylus avellana L., Diospyros lotus L., Acer campestre L. olarak belirlenmiştir. Bu türlere ek olarak Euphorbia amygdaloides L., Helleborus orientalis Lam., Primula vulgaris Huds., Rubus hirtus Waldst\&kit, Ruscus aculeatus L., Ruscus hypoglossum L., Smilax aspera L., Smilax excelsa L., Viola sieheana W. Becker gibi bitki bitkilerin ıhlamura eşlik eden türler arasında olduğu belirtilmiştir (Stanescu et al. 1997; Özel vd. 2017).

\section{Çiçek Yağ Verimleri}

Yapılan çalışmada 100 gram çiçekten elde edilen ortalama yağ $0.09 \mathrm{ml}$ olarak bulunmuştur. Yörelere göre 100 gram çiçek örneklerinden elde edilen ortalama yağ miktarları Karacabey'de $0.11 \mathrm{ml}$, Yalova'da $0.07 \mathrm{ml}$ ve Bursa'sa 0.05 ml'dir (Çizelge 1). En yüksek yağ miktarı Karacabey'den, en düşük Bursa'dan alınan örneklerde bulunmuştur. Literatür verileriyle karşılaştııılıı̆ında $T$. platyphyllos yaprak ve çiçeklerinde yağ oranı sadece $\% 0.03$ düzeyinde bulunurken, $T$. rubra ve $T$. tomentosa'da bu oranın daha düşük olduğu belirtilmektedir (Toker vd. 1999). Yapılan bir başka çalışmada ise yağ oranı \%0.02-\% 0.1 arasında (Anonymous 2012) değişmekte olup bulgularımızla uyum göstermektedir.

Çiçeklerdeki nem içeriği Yalova'dan toplanan örneklerde daha yüksek düzeyde bulunmuştur. Toplanan çiçeklerde brahte büyüklükleri farklılık gösterdiğinden kuru ağırık olarak çiçek/brahte oranlarında yöreler arasındaki farklar belirlenmiştir. Bursa'dan toplanan örneklerde bu oranın daha fazla olduğu görülmektedir. Çiçek toplanan rakımlar kademelendirilerek (0-200 m, 201-400 m, 401-600 m) yapılan istatistiki analizlerde rakımın çiçek yağ miktarını etkilediği belirlenmiştir. 0-400 m. rakımlar arasındaki yağ miktarı daha yüksek bulunmuştur. Arazi eğimi ve bakının ise yağ miktarına etkisinin olmadığı belirlenmiştir (Çizelge 1).

Çizelge 1. Ihlamur çiçeği yağ miktarlarının toplama yeri, rakım, eğim ve bakıya göre değişimi

\begin{tabular}{|c|c|c|c|c|c|c|c|c|c|}
\hline \multirow{2}{*}{$\begin{array}{l}\text { Mevki } \\
\text { Karacabey }\end{array}$} & \multirow{2}{*}{$\begin{array}{c}\text { Yağ miktarı } \\
\text { (F:4,832**) }\end{array}$} & \multirow{2}{*}{$\begin{array}{c}\text { Çiçek/brahte } \\
\text { oranı (F:4.642*) } \\
1.9 a\end{array}$} & \multirow{2}{*}{$\begin{array}{c}\text { Nem içeriği (\%) } \\
\text { (F:29.430**) }\end{array}$} & \multicolumn{2}{|c|}{ Rakım (m) (F:3.636*) } & \multicolumn{2}{|c|}{$\begin{array}{c}\text { Eğim (\%) } \\
\left(\mathrm{F}: 0.711^{\text {ns }}\right)\end{array}$} & \multicolumn{2}{|c|}{ Bakı (F:2.645 $\left.{ }^{\text {ns }}\right)$} \\
\hline & & & & $0-200$ & $0.11 \mathrm{a}$ & $0-40$ & 0.09 & Doğu & 0.05 \\
\hline Yalova & $0.07 a b$ & $1.8 \mathrm{a}$ & $89 a$ & $201-400$ & $0.09 \mathrm{a}$ & $41-70$ & 0.08 & Batı & 0.07 \\
\hline \multirow[t]{2}{*}{ Bursa } & $0.05 \mathbf{b}$ & $2.3 b$ & $76 \mathrm{c}$ & $401-600$ & 0.04 b & $71-100$ & 0.11 & Kuzey & 0.11 \\
\hline & & & & & & & & Güney & 0.07 \\
\hline
\end{tabular}

*işlemler arasında \%5 önem düzeyinde anlamlı farklılık olduğunu ifade etmektedir. **işlemler arasında \%1 önem düzeyinde anlamlı farklılık olduğunu ifade etmektedir; ns İşlemler arasında fark olmadığını ifade etmektedir; Harflerdeki farklılıklar işlemler arasındaki farklılığı ifade etmektedir.

Çiçek yağ veriminde, taç yönü, kapalılık gibi faktörlerin etkisi araştırımıştır. Çiçeklerin tomurcuk ve tam açma durumları arasında beş sınıflama yapılarak yağ verimine etkisi incelenmiştir. Toplanan çiçeklerde farklı renk durumlarına göre de sınıflaması yapılarak yağ verimleri belirlenmiş, fakat yapılan istatistiki analizlerde tüm bu faktörlerin yağ verimi üzerinde etkili olmadığı görülmüştür (Çizelge 2).

\section{SONUÇ ve ÖNERILER}

Yağ verimi bakımından populasyonlar arasında fark bulunmuştur. Klonal üretim ve plantasyon kurma çalışmalarında yağ verimi yüksek populasyonların tercih edilmesi doğru bir yaklaşım olacaktır. Yükseltinin yağ verimi üzerinde etkisi ortaya konmuş, alçak rakımlarda yağ veriminin daha yüksek olduğu belirlenmiştir. Bu bakımdan plantasyonların 0-400 m. arasında tesis edilmesi tavsiye edilebilir. Eğim ve arazi bakısının yağ verimine etkisinin olmadığı görülmektedir.

Toplanan çiçeklerin tomurcuk veya tam açmış olması yağ verimini etkilememektedir. Bu bakımdan erken tomurcuk döneminde de çiçekler toplanabilir. Ağacın taç yönü ve kapalıı̆ı̆ın da yağ verimini ekilemediği ortaya konulmuştur. Çiçek renginin yağ verimi üzerinde etkisi belirlenememiştir. Ağacın taç çapı, müdahale görüp görmediği gibi hususların da çiçek yağ verimini etkilememektedir. 
Çizelge 2. Ihlamur çiçeği yağ miktarlarının çiçeklenme durumu, taç yönü, kapalılık ve çiçek rengine bağlı değişimi

\begin{tabular}{|c|c|c|c|c|c|c|c|}
\hline \multicolumn{2}{|c|}{ Çiçeklenme durumu (F:2.053 ${ }^{\text {ns }}$ ) } & \multicolumn{2}{|c|}{ Taç yönü (F:2.053ns) } & \multicolumn{2}{|c|}{ Kapalılık (\%) (F:0.901 $\left.{ }^{\text {ns }}\right)$} & \multicolumn{2}{|c|}{ Çiçek rengi (F:3.093ns) } \\
\hline Tomurcuk & 0.10 & Doğu & 0.08 & Gevşek (10-40) & 0.06 & Yeşil & 0.07 \\
\hline$\% 25$ açmış & 0.15 & Batı & 0.08 & Orta $(41-70)$ & 0.09 & Açık sarı & 0.11 \\
\hline$\% 50$ açmış & 0.12 & Kuzey & 0.11 & $\operatorname{Tam}(>71)$ & 0.09 & Koyu sarı & 0.12 \\
\hline$\% 75$ açmış & 0.08 & Güney & 0.09 & & & & \\
\hline$\% 100$ açmış & 0.07 & & & & & & \\
\hline
\end{tabular}

*işlemler arasında \%5 önem düzeyinde anlamlı farkılıı olduğunu ifade etmektedir. **işlemler arasında \%1 önem düzeyinde anlamlı farklıık olduğunu ifade etmektedir;

ns iş̧lemler arasında fark olmadığını ifade etmektedir; Harflerdeki farklılıklar işlemler arasındaki farklıı̆̆ı ifade etmektedir

\section{TEŞEKKÜR}

Bu çalışma Bursa Teknik Üniversitesi Bilimsel Araştırma Projeleri Birimi tarafından desteklenmiştir (Proje Numarası: 171 L 22). 4-6 Ekim 2018 tarihinde 4. Uluslararası Odun Dışı Orman Ürünleri Sempozyumunda özet bildiri olarak sunulmuştur.

\section{KAYNAKLAR}

Aguirre-Hernandez E, Martinez AL, Gonzalez-Trujano ME, Moreno J,Vibrans H, Soto-Hernandez M (2006) Pharmacological evaluation of the anxiolytic and sedative effects of Tilia americana L. var.mexicana in mice. J. Ethnopharmacol. 109,140-145.

Akbulut S, Bayramoğlu MM (2013) The Trade and Use of Some Medical and Aromatic Herbs in Turkey. EthnoMed, 7(2): 67-77.

Allio A, Calorio C, Franchino C, Gavello D, Carbone E (2015) Bud extracts from Tilia tomentosa Moench inhibit hippocampal neuronal firing through $\operatorname{GAB}(\mathrm{A})$ and benzodiazepine receptors activation. Journal of Ethnopharmacology 172, 288-296.

Alston C (1770) Lectures on the Materia Medica. Edward and Charles Dilly, London.

Anonymous (2012) Assessment report on Tilia cordata Miller, Tilia platyphyllos Scop.,Tilia $x$ vulgaris Heyneor their mixtures, flos EMA/HMPC/337067/2011.

Bayram E, Kırıcı E, Tansi S, Yılmaz G, Arabacı O, Kızıl S, Telci i (2010) Tıbbi ve Aromatik Bitkiler Üretiminin Arttırılması Olanakları, Ziraat Mühendisliği VII. Teknik Kongresi, Bildiriler Kitabı-1, 11-15 Ocak 2010 Ankara, Say. 437-457.

Baytop A (1996) Farmasötik Botanik, İstanbul Üniversitesi Yayınları No:3637, Eczacılık Fakültesi Yayın No:58. İstanbul.

Baytop T (1999) Türkiye'de Bitkiler ile Tedavi, Nobel Tıp Kitabevleri, İstanbul.

Birbilener S (2015) Düzce İçi Şehir Ekosisteminde Dağılım Gösteren Ihlamur Ağaçlarında (Tilia tomentosa Moench.) Genetik Çeşitliliğin RAPD İşaretleyicileriyle Araştırılması, Yüksek Lisans Tezi, Marmara Üniversitesi Fen Bilimleri Enstitüsü.

Bradley P (1992) British Herbal Compendium. Vol. I. Dorset (Great Britain): British Herbal Medicine Association, 142-144.

Cardenas-Rodriguez N, Gonzalez-Trujano ME, Aguirre-Hernandez E, Ruiz-Garcia M, Sampieri A, Coballase-Urrutia E, Carmona-Aparicio $L$ (2014) Anticonvulsant andantioxidant effects of Tilia americana var.mexicana and flavonoids constituents in the pentylenetetrazole-induced seizures. Oxid.Med. Cell. Longev.2014,759293.

Chinou I (2012) Assessment report on Tilia tomentosa Moench, flos. European Medicines Agency, Committee on Herbal Medicinal Products., 346780/2011.

Craig WJ (1999) Health-Promoting Properties Of Common Herbs. Am J Clin Nutr; 70: 491-9. Doi. 10.1093/ajcn/70.3.491s.

Çepel N (1988) Toprak İlmi Ders Kitabı, İstanbul Üniversitesi Orman Fakültesi Yayınları, i..Ü. Yayın No 3416, OF yayın no: 389, 276 s. İstanbul.

Davis P H (1967) Flora of Turkey and the East Aegean Islands, Vol: II, Edinburgh University Press, Edınburgh.

Gegiu A (2008) Contributions to the knowledge of the composition of essential oils from Tilia tomentosa, Tilia americana and Tilia platyphyllos, Botany \& Physiology Lucrări G̦tiinţifice U.g.A.M.V.B., Seria B, vol. LI, 2008, 570-572.

Georgiev YN, Ognyanov MH, Kiyohara H, Batsalova TG, Dzhambazov BM, Ciz M, et al. (2017) Acidic polysaccharide complexes from purslane, silver linden and lavender stimulate Peyer's patch immune cells through innate and adap-tive mechanisms. International Journal of Biological Macromolecules, http://dx.doi.org/10.1016/j.ijbiomac.2017.07.095.

Gruenwald J, Brendler T, Jaenicke C (2000) PDR for Herbal Medicines. 2nd ed.,Thompson-Physicians' Desk Reference, 477-478.

Güner, A., Aslan, S., Ekim, T., Vural, M., ve Babaç, M.T. (edlr.) (2012). Türkiye Bitkileri Listesi Damarlı Bitkiler, Nezahat Gökyiğit Botanik Bahçesi Botanik Bahçesi ve Flora Araştırmalı Derneği Yayını, Flora Dizisi 1, İstanbul.

Herrera-Ruiz M, Roman-Ramos R, Zamilpa A,Tortoriello J, JimenezFerrer JE (2008) Flavonoids from Tilia americana with anxiolytic activity in plus-maze test. J. Ehnopharmacol. 118: 312-317.

Leri F, Innocenti M, Possieri L, Gallori S, Mulinacci N (2015) Phenolic composition of "bud extracts" of Ribes nigrum L., Rosa canina L. and Tilia tomentosa M. Journal of Pharmaceutical and Biomedical Analysis 115: 1-9.

Kalmukov K (1994) Studies on eco- and - biotype diversity of Tilia tomentosa Moench. in Northern Bulgaria. - Proc. Jubilee Symposium (2-3 June 1994) 100 years from birthday of the Acad. Boris Stefanov, vol. I, Sofia, 82-85.

Kıvrak Ş, Göktürk T, Kıvrak i (2017) Determination of Phenolic Composition of Tilia Tomentosa Flowers Using UPLC-ESI-MS/MS, Int. J. Sec. Metabolite, Vol. 4: 3, pp. 249-256.

Korkut S (2011) Physical and mechanical properties and the use of lesser-known native Silver Lime (Tilia argentea Desf.) wood from Western Turkey. African Journal of Biotechnology Vol. 10(76), pp. 17458-17465. 
Loscalzo LM, Wasowski C, Marder M (2009) Neuroactive flavonoid glycosides from Tilia petiolaris DC. extracts. Phytother Res 23,1453-1457.

Özel N, Öner H, Akbin G, Altun N, Özkan K (2017) Karadağ (BursaBalıkesir) Bitki Toplumlarının Belirlenmesi (Identification of Plant Communities in Karadağ (Bursa-Balıkesir), Yayınlanmamış proje raporu, Ege Ormancılık Araştırma Enstitüsü Müdürlüğü.

Özen F (2004) Ihlamur Ağacı ve bal, Uludağ Arıcılık Dergisi, 2004: 149150.

Özyurt S (1992) Ekonomik Botanik, Erciyes Üniversitesi Yayınları, No: 47, Kayseri.

Özyuvacı N (1999) Meteoroloji ve Klimatoloji, i.ü. Orman Fakültesi Yayınları, Rektörlük No: 4196, Fakülte No: 460, ISMN: 975-404544-5, İstanbul.

Peev C, Dehelean C, Antal D, Feflea S, Olariu L, Toma C (2009) Tilia tomentosa foliar bud extract: phytochemical analysis and dermatological testing. Studia Universitatis Vasile Goldis, Seria Stiintele Vietii 19: 163-165.

Sıralı R, Deveci M (2002) Bal arısı (Apis mellifera L.) için önemli olan bitkilerin Trakya Bölgesinde incelenmesi Uludag Arıcılık Dergisi 2(1):17-26.

Sorkun K (1995) Türkiye'nin önemli nektar kaynağı olan kültür bitkileri ve bal potansiyelleri, Türkiye 2. Teknik Arıcılık Kongresi, T.C. Ziraat Bankası Matbaası, 134-149.

Stanescu V, Sofletea N, Popescu O (1997) Flora forestiera lemnoasa a Romaniei. Editura Ceres, Bucuresti.

Şahin N, Özdemir M, Tandoğan M, Sezgin G, Arslan A, Sezik E, Yeşilada E, Güzelmeriç E (2018) Marmara Bölgesinde Gümüşi Ihlamurun (Tilia tomentosa Moench) Çiçek Kalitesi Üzerine Araştırmalar, Marmara Ormancılık Araştırma Enstitüsü Müdürlüğü, Yayınlanmamış Proje Raporu, (Proje numarası: 10.7701/2013).
Tan A (2010) Türkiye Gıda ve Tarım Bitki Genetik Kaynaklarının Durumu Gıda ve Tarım İçin Bitki Kaynaklarının Muhafazası ve Sürdürülebilir Kullanımına İlişkin Türkiye İkinci Ülke Raporu, ETAE Yayın No:141, Bornova, ISBN:978975407292.

Thorntwaite CW (1948) An Approach to a Rational Classification of Climate. Geographic Review, 38: 55- 94.

Toker G, Başer KHC, Kürkçüoğlu M, Özek T (1999) The Composition of Essential Oils from Tilia L. Species Growing in Turkey, Journal of Essential Oil Research, 11: 369-374.

Toker G, Memişoğlu M, Yeşilada E, Aslan M (2004) Main Flavonoids of Tilia argentea DESF. ex DC. Leaves. Turk J Chem, 28: 745-749.

Toker MC, Toker G, Yılmazer R (1997) Ihlamur (Tilia) meyvaları üzerinde morfolojik ve anatomik çalışmalar. Ankara Eczacılık Fakültesi Dergisi, 26 (2): 89-94.

Tsoumis G (2002) Science and technology of wood. Aristotle University of Thessaloniki.

Tuttu G, Ursavaş S, Söyler R (2017) Ihlamur Çiçeğinin Türkiye'deki Hasat Miktarları ve Etnobotanik Kullanımı Anadolu Orman Araştırmaları Dergisi, 3 (1) 60-66.

URL

https://www.ogm.gov.tr/ekutuphane/Sayfalar/Istatistikler.aspx(son erişim 13.7.18).

Uslu J (2004) Ihlamur sektörü profili, İstanbul Ticaret Odası bilgi ve döküman yönetimi şubesi.

Vinson JA, Dabbagh YA, Serry MM, Jang J (1995) Plant Flavonoids, Especially Tea Flavonoids, Are Powerful Antioxidants Using An Ġn Vitro Oxidation Model For Heart Disease. J Agric Food Chem. 43: 2800-2.

Viola H, Wolfman C, Levi de Stein M, Wasowski C, Pena C, Medina JH, Paladini AC (1994) Isolation of pharmacologically active benzodiazepine receptor ligands from Tilia tomentosa (Tiliaceae). Journal Ethnopharmacology. 44: 47-53. 